\title{
Working
}

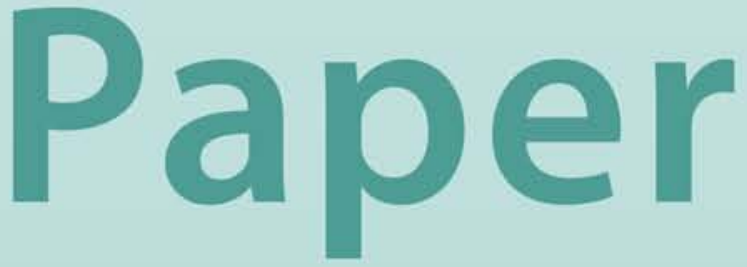


Population Aging in Japan: Demographic Shock and Fiscal Sustainability

Hamid Faruqee and Martin Mühleisen 


\title{
IMF Working Paper
}

Research and Asia and Pacific Departments

\section{Population Aging in Japan: Demographic Shock and Fiscal Sustainability}

\author{
Prepared by Hamid Faruqee and Martin Mühleisen ${ }^{1}$ \\ Authorized for distribution by Peter Isard and Jonathan D. Ostry
}

April 2001

\begin{abstract}
The views expressed in this Working Paper are those of the author(s) and do not necessarily represent those of the IMF or IMF policy. Working Papers describe research in progress by the author(s) and are published to elicit comments and to further debate.
\end{abstract}

The paper develops a general equilibrium framework to examine the economic implications of population aging in Japan. Particular attention is paid to aggregate saving behavior which is modeled on the basis of empirical age-earnings profiles using a life-cycle approach. The paper's objectives are to (i) estimate the output loss caused by demographic changes and assess the impact of aging on Japan's government finances; and (ii) compare fiscal policy options with respect to their effects on output growth and economic welfare.

JEL Classification Numbers:D58, E21, E27, E62

Keywords: Japan, aging, saving, fiscal policy, general equilibrium analysis

Author’s E-Mail Address: hfaruqee@,imf.org; mmuhleisen@imf.org

\footnotetext{
${ }^{1}$ The authors wish to thank Charles Collyns, Jonathan D. Ostry, participants at an APD research seminar and four anonymous referees for valuable comments. Excellent research assistance by Susanna Mursula and Sarma Jayanthi is also gratefully acknowledged.
} 


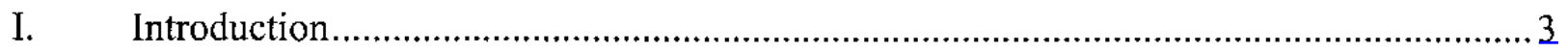

II. Changing Demographics and the Fiscal Problem .......................................................

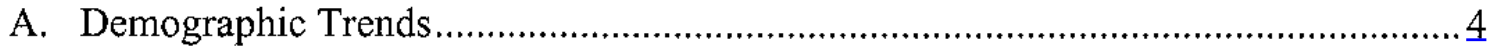

B. The State of Government Finances ..................................................................... 6

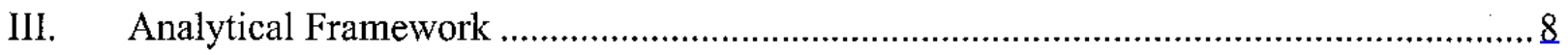

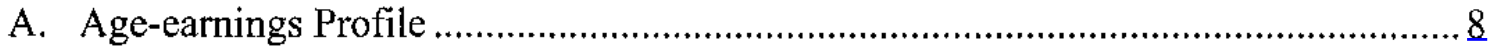

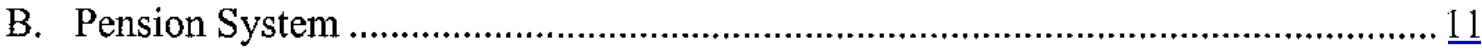

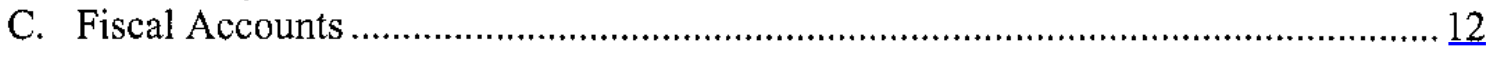

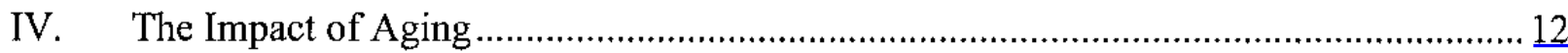

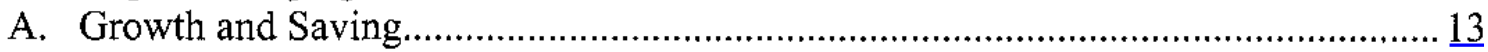

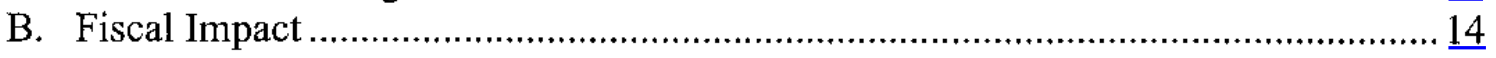

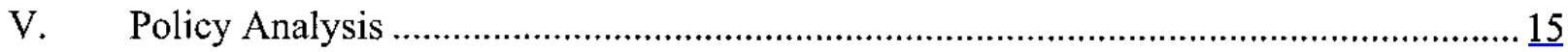

A. How to Address the Aging Problem? ............................................................ 15

B. Speed and Composition of Fiscal Consolidation ..................................................18

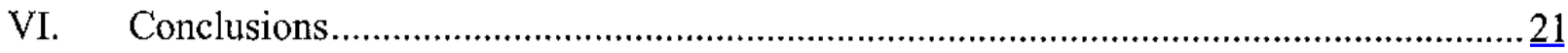

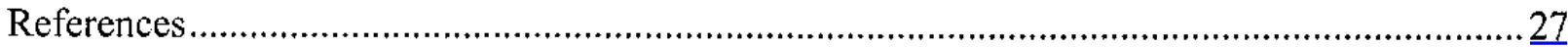

Tables

1. Old-Age Dependency Ratios: Comparative Projections..................................................

2. General Government Finances, 1999 ........................................................................

3. Simulated Effects of Population Aging in Japan .....................................................13

4. Comparative Effects of Demographic Changes in Japan .......................................... 25

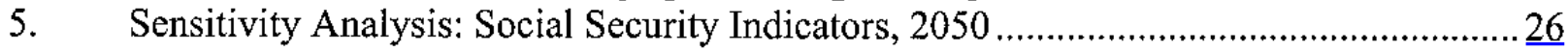

Figures

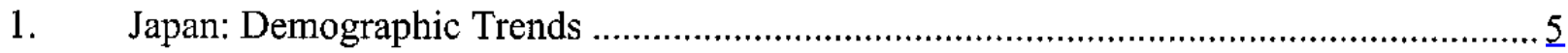

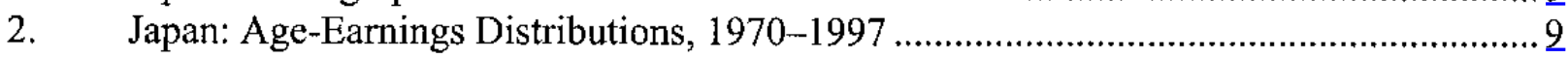

3. Japan: Macroeconomic Effects of Social Security Reform .........................................17

4. Japan: Macroeconomic Effects of Fiscal Consolidation Strategies ................................20

5. Japan: Birth Rate and Population Growth Rate, 1990-2150 ……………………......23

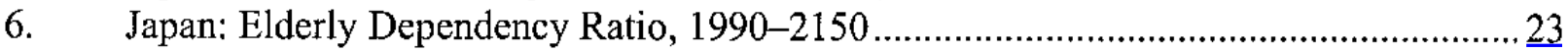

7. Japan: Birth Rate and Population Growth Rate, 1990-2150 …..................................24

8. Japan: Elderly Dependency Ratio, 1990-2150 ........................................................24

Appendices

I. Demographic Impact and Counterfactual Scenarios.................................................23

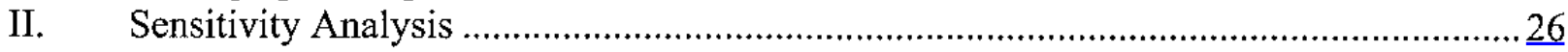




\section{INTRODUCTION}

Demographic changes pose a serious policy challenge in the industrialized world. There is broad consensus among economists that population aging will reduce output growth and limit increases in economic welfare in most OECD countries over the coming decades (e.g., Kohl and O'Brien 1998, OECD 1998). An older population will be associated with lower levels of employment and output, although the impact on per-capita income could be mitigated by rising capital-labor ratios, productivity increases, and higher labor participation rates. The ability of fiscal policy to mitigate the effects on living standards will be limited, owing to the demand for higher spending on public pensions and health services for the elderly.

Japan will be particularly affected by this process. Its population enjoys the highest longevity worldwide, and the share of elderly people relative to the working population is already among the highest. By contrast, fertility rates are among the lowest in the world, implying a declining population and an age distribution that will continue to shift rapidly in the coming decades. By 2025 , one elderly person will fall on roughly two persons of working age, which will leave Japan with a significantly higher old-age dependency ratio than any other country in the industrialized world. Japan's fiscal challenge is also substantially larger than in other countries. While most industrialized nations have successfully reduced government deficits in recent years, Japan's fiscal situation deteriorated dramatically following the government's efforts to resuscitate the economy during the past decade. Therefore, as the country embarks on the longterm task of preserving the social security system, it will first have to return the fiscal deficit to a sustainable level.

Most of the models used to analyze the effects of demographic shocks have focused on the broad macroeconomic picture, with government finances being modeled on a fairly aggregate basis, and demographic effects largely being captured through simple dependency ratios (Masson and Tryon 1990, Yashiro and Oishi 1997). A more pragmatic strand of the literature has focused on the implications of demographics for fiscal and pension policies (including models used by the Japanese government itself), but has largely neglected the feedback effects with the macro economy. As a result, most of the existing models are unsuitable to answer questions of primary importance to policymakers, such as the degree and type of consolidation required to maintain fiscal sustainability, and the costs and benefits of different fiscal policy strategies. $^{2}$

This paper attempts to fill the gap by developing a simulation framework using MULTIMOD, the Fund's general equilibrium model, to examine the economic implications of population aging in Japan as well as the policies designed to address it:

\footnotetext{
${ }^{2}$ Exceptions are macroeconomic models used by Aaron et al. (1989) for the United States, and Yashiro et al. (1997) for Japan - based on the 1994 pension reform-which have embedded in them explicit models for the finances of the social security system.
} 
- The paper introduces demographic features into MULTIMOD. The macroeconomic effects of demographic changes are modeled through two channels: (i) on the supply side, changes in the age structure have implications for labor supply; and (ii) on the demand side, population aging has implications for aggregate consumption, saving, and investment. The model is calibrated using age-earnings and demographic data for Japan and other industrial countries. To allow policy analysis, the model also introduces a social security transfer scheme.

- The general equilibrium framework is combined with a more detailed model of the fiscal accounts to look into the degree and costs of fiscal adjustment needed to stabilize public debt over the medium term, and to analyze policy responses that would safeguard the viability of the social security system while mitigating the impact on long-term economic growth.

The paper is organized as follows. The demographic and fiscal challenges facing Japan are outlined in the next section, which is followed by a description of the analytical framework that forms the basis for the simulations. A baseline simulating the impact of aging on economic growth is discussed in section IV. Section V analyzes the consequences of different fiscal policy choices, and a final section concludes.

\section{Changing Demographics and the Fiscal Problem}

\section{A. Demographic Trends}

A central feature of Japan's demographics is a long-run decline in fertility. In the postwar era, the total fertility rate - defined as the number of births per woman-experienced a sharp decline in a single ten-year span, falling from over $3 \frac{1}{2}$ births in 1950 to just 2 births in 1960 (top panel of Figure 1). Since that time, the fertility rate has continued its general decline, and now remains well below the replacement rate. ${ }^{3}$ Population projections generally assume the fertility rate to eventually stabilize and increase towards the replacement rate in order to obtain a stationary population by the middle of the century, but the expected point in time for the recovery to set in has been pushed back with every new projection.

The implication of the dramatic fall in fertility is that, for some time to come, fewer young workers are expected to enter the economy. Redefining "births" as the inflow of new adults into the economy, the middle panel of Figure 1 shows the historical and projected evolution of Japan's "birth rate" since 1960. As evident in the graph, the inflow of young adults as a share of the adult population has declined significantly over the past 40 years; moreover, even assuming

\footnotetext{
${ }^{3}$ Takayama (1998) cites three factors behind the decline in fertility rates in Japan: first, a decrease in the salary gap between men and women; second, difficulties reconciling work with child rearing; and third, a generous social security system to provide adequate living standards for the elderly.
} 
Figure 1. Japan: Demographic Trends

Total Fertility Rate, 1950-2050

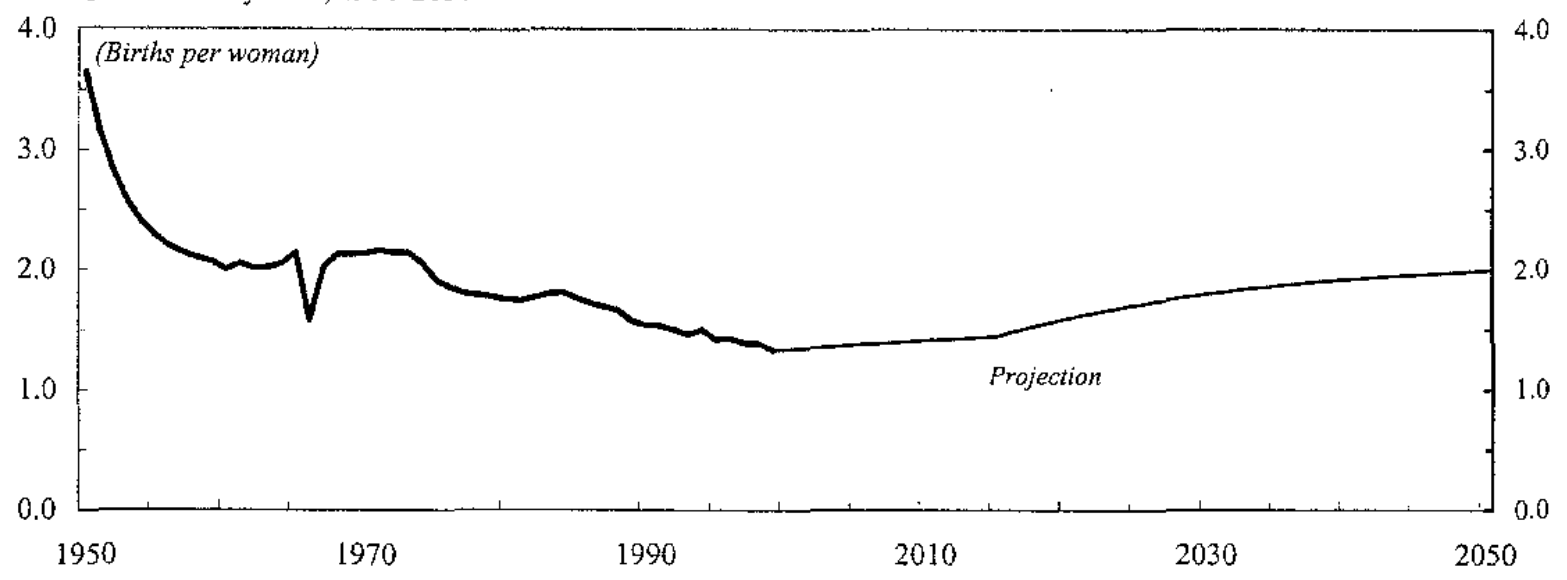

Birth Rate and Population Growth Rate, 1960-2150 1/

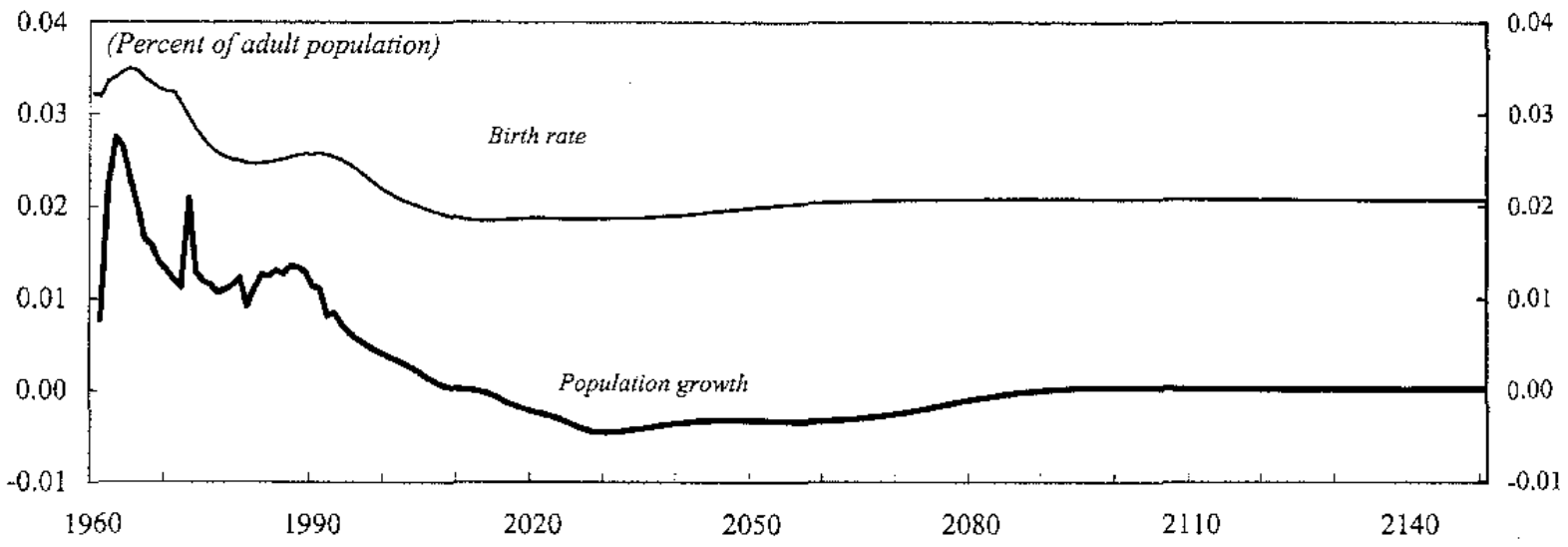

Elderly Dependency Ratio, 1960-2150

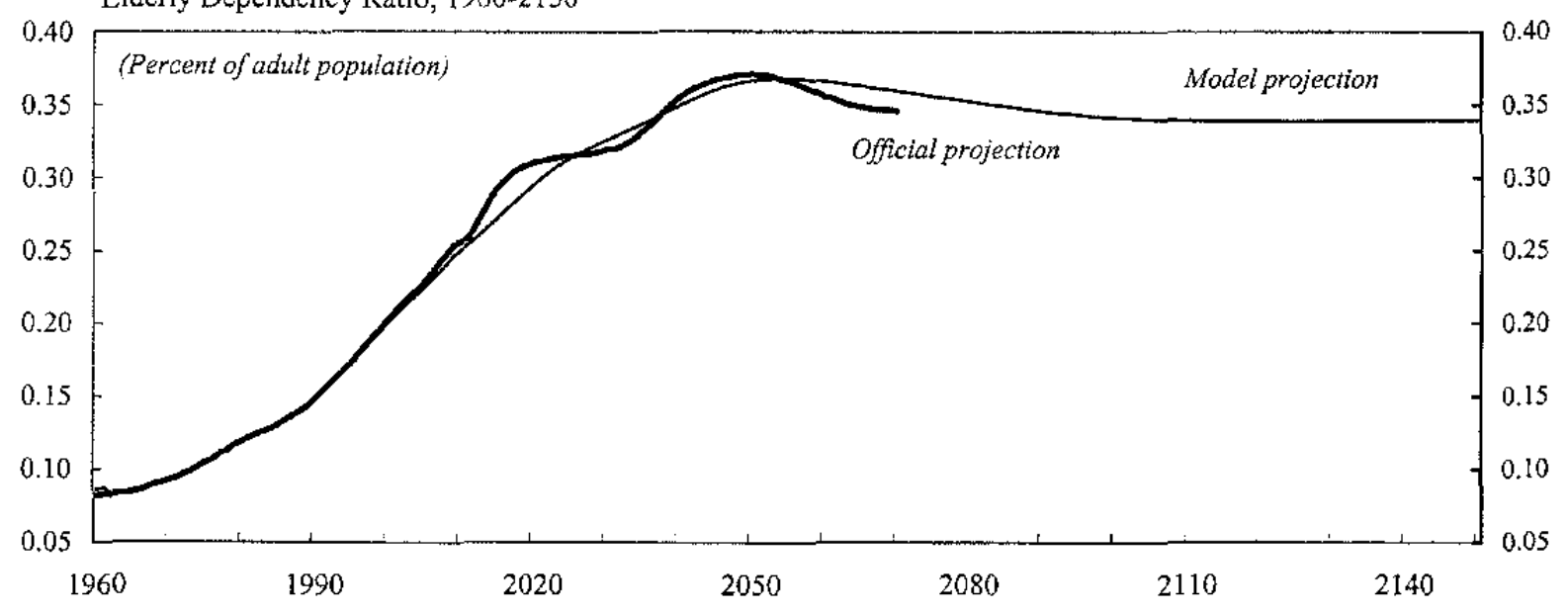

Sources: Takayama (1998); Bos et al. (1994); Ministry of Health and Welfare; and staff estimates.

1/ "Birth" rate is defined as the entry of workers into the adult population. 
a modest recovery in fertility rate over the next fifty years, the "birth rate" is projected to remain far below its historical levels well into the next century. ${ }^{4}$ This does not assume any population increase due to immigration, which has alleviated demographic pressures elsewhere.

The long-run decline in Japan's birth rate implies that Japan will have both a declining and an aging population. As seen in Figure 1, the decline in the "birth rate" is associated with a decline in the population growth rate. In fact, fertility rates have already fallen to such an extent that a declining adult population can be expected for much of the $21^{\text {st }}$ century-a development not anticipated in most industrialized countries. With lower fertility and smaller cohorts of new adults arriving in the future, the relative share of working age people will decline and the population's average age will increase over time. The bottom panel in Figure 1 shows the dramatic rise in the ratio of Japan's elderly dependents (age 65 and over) as a share of the adult population, based on the analytical model as well as projections by the Ministry of Health and Welfare. ${ }^{5}$ The sharp decline in fertility is expected to generate a more rapid aging of Japan's population than in other major industrial countries (Table 1).

\begin{tabular}{|lccccccc}
\hline \multicolumn{7}{|c|}{ Table 1. Old-Age Dependency Ratios: Comparative Projections } \\
\hline \\
\hline Canada & France & Germany & Italy & U.K. & U.S. & Japan \\
\hline 2000 & 20 & 28 & 25 & 28 & 27 & 21 & 27 \\
2025 & 36 & 41 & 36 & 43 & 36 & 33 & 47 \\
\hline Source: United Nations, World Population Prospects, 1950-2050, 1996 revisions. \\
${ }^{1}$ Number of elderly (65 years and older) as percent of working age population (20-64 years of age). \\
\hline
\end{tabular}

\section{B. The State of Government Finances}

As this demographic shock unfolds, Japan will face a substantially greater fiscal challenge than other countries. While most industrial nations have successfully reduced government deficits during the past decade, Japan's fiscal situation deteriorated dramatically following the government's efforts to resuscitate the economy during the past decade. Tax revenues receded strongly after the collapse of the asset price bubble in the early 1990s, and expenditures have been driven upward by economic stimulus measures, above all the strong increase in public works spending (Mühleisen 2000a). As a result, the general government deficit has reached an

\footnotetext{
${ }^{4}$ To be consistent with the model described later, the focus here is on the adult population (i.e., age 15+), and the birth rate is defined as the arrival rate of new adults or workers. Correspondingly, growth rates refer to the percent change of the adult population. In Figure 2, historical data and projections for the "birth" rate are constructed from data on the youngest adult cohort group - i.e., 15-24 year olds-to yield the share of new adults arriving each period; this series resembles movements in the more conventional fertility rate shown in Figure 1 with a 20-year lag.

${ }^{5}$ Details of the model can be found in Faruqee $(2000,2001)$.
} 
estimated 9 percent of GDP in FY1999 (excluding the social security surplus), and even if Japan's cyclical position is taken account of, the structural deficit remains worse than that of other G-7 countries (Table 2).

Although Japan's net general government debt still appears relatively small (at 40 percent of GDP in 1999), this figure includes assets owned by the social security system-accounting for 50 percent of GDP - which are more than offset by future pension claims. If social security assets are excluded, Japan's debt situation is considerably worse than that of other industrialized countries. General government debt (excluding social security) has roughly doubled over the past decade, and markets have been concerned that the true level of public debt could be even higher, given the possibility that the government might have to cover contingent liabilities from loan guarantees and losses by public sector enterprises.

\begin{tabular}{|lccccccc}
\hline \multicolumn{7}{|c|}{ Table 2. General Government Finances, 1999} \\
(In percent of GDP)
\end{tabular}

How will population aging affect government finances? Given the fact that the government currently finances roughly 20 percent of social security benefits, an increase in pension payments and costs of health services for the elderly will impact directly on the expenditure side, while revenue prospects would be affected by the slower economic growth. Chand and Jaeger (1996) estimated the present value of Japan's net pension liabilities around 110 percent of GDP, and similar results were obtained by Leibfritz et al. (1995) and Roseveare et al. (1996) ${ }^{6}$ Broadly consistent with these findings, the Ministry of Health and Welfare (based on detailed actuarial assumptions) estimated that the main public pension system would need to raise contribution rates to $1 \frac{1}{2}$ times their current level over the next 25 years to remain viable.

Both the size of the current deficit and the demographic outlook indicate that the current fiscal situation is clearly unsustainable and requires strong adjustment measures in coming years. However, the problem for the authorities lies in addressing the fiscal imbalance in a way that will not jeopardize the nascent economic recovery. In 1997, the last attempt at fiscal consolidation had to be abandoned as a rise in the consumption tax rate and a cut in public works spending were among the factors contributing to the renewed economic downturn.

\footnotetext{
${ }^{6}$ The 2000 pension reform has reduced this liability by about a third (see below).
} 
Although factors other than fiscal policy were at work on that occasion, the principle that fiscal consolidation needs to take account of evolving economic and financial conditions-including the robustness of the recovery-remains a valid one.

\section{ANALYTICAL FRAMEWORK}

The analytical framework of this paper is based on MuLTimod, the Fund's global macroeconomic simulation model. ${ }^{7}$ The standard model is modified in three key points. First, demographic dynamics based on the projections discussed earlier are incorporated into the model. Second, a life-cycle dimension to agents' behavior is introduced through age-earnings profiles, calibrated from official survey data. And third, the model explicitly includes a social security transfer scheme. Pension policy parameters, thus, directly enter private agents' decision making process and allow the model to examine the economic impact of social security reforms in the context where the private sector endogenously responds to those policy reforms. Points two and three are further elaborated below. ${ }^{8}$

\section{A. Age-earnings Profile}

A key component to the analysis of demographic effects is the nature of the earnings profile over an individual's lifetime, which typically has a hump-shaped pattern. Initially, as agents join the workforce, they can expect a rising path of earnings, reflecting productivity gains that come from work experience and seniority wages that reward past service. Eventually, labor earnings level off and decline as agents move into retirement. This life-cycle earnings profile is important in determining both supply and demand-side effects of population aging.

On the supply side, age-earnings profiles provide an indicator of the changes in relative productivity and labor supply that occur over an individual's working life. To the extent that earnings differences are commensurate with differences in labor productivity, the income profile provides a measure of these life-cycle changes in labor supply (measured in efficiency units). Demographics changes in the population's age-structure can thus affect aggregate labor supply through age differences in relative productivity and individual labor supply.

On the demand side, the anticipated path of labor income influences the saving plans of consumers over their lifetimes. Consumption/saving propensities vary by age as consumers choose to smooth consumption in the face of life-cycle income. Younger agents tend to be net borrowers, reflecting the fact that permanent income exceeds current income (see Jappelli 1990, Attanasio et al. 1995). Mature agents tend to be large net savers at the peak of their earnings potential and in anticipation of retirement. Meanwhile, the elderly-who consume largely out of

${ }^{7}$ MULTIMOD is a dynamic multi-country general-equilibrium model with forward-looking behavior and model-consistent expectations. See Laxton et al. (1998) for a description and, e.g., Faruqee et al. (1997) for an application of the model.

${ }^{8}$ For computational purposes, MULTIMOD is reduced to four major country blocks-Japan, the U.S., other industrial countries, and the rest of the world. 
asset income and transfers-also tend to save (albeit to a lesser degree), reflecting precautionary saving in the face of lifetime uncertainty (see Blanchard 1985, Faruqee and Laxton 2000). ${ }^{9}$ Changes in the demographic structure of the population can thus have important macroeconomic implications for aggregate saving, stemming from these various life-cycle channels.

To calibrate the model according to the lifecycle pattern of earnings, empirical ageearnings profiles for Japan are estimated using cross-sectional data on wage-based salaries by age group for the period 1970 to 1997. The data are adjusted by labor force participation rates, reflecting the fact that the share of persons with zero earnings varies across age groups. The earnings profile thus represents the average earnings per person (not per worker) within each age category. The data are shown in Figure 2, normalized relative to per capita labor earnings of the youngest cohort. ${ }^{10}$ The relative earnings profiles have been stable over the sample period which suggests that the underlying institutional and structural features that implicitly underpin the variation in relative labor earnings across age groups--such as seniority wages and retirement age--have also been fairly stable historically.

${ }^{9}$ On this last point, unlike traditional life-cycle models - e.g., Diamond (1965) - the elderly do not dissave or run down financial assets here due to life-time uncertainty. Instead, with retirement, agents build up wealth to some target level as a precaution against the possibility of remaining alive without labor income. See also Davies (1981) and Abel (1985). This behavioral feature allows the multi-cohort framework to avoid a common criticism of standard life-cycle models that posit large negative saving rates among retirees, not found in the data; see Browning and Lusardi (1996). Hayashi (1986) argues that positive saving among the elderly in Japan favors models with bequest motives over the life-cycle approach. Yashiro et al. (1997) argue, however, that in the case of Japan the micro data tend to overstate the positive saving rates of the elderly by under-representing poorer agents who reside with younger family members.

${ }^{10}$ Data are based on contract wages by age, adjusted for labor force participation and employment rates, as reported in the Statistical Yearbook; the earnings data are combined for both male and female workers for the following age categories: 15-24, 25-29, 30-34, 35-39, $40-44,45-49,50-54,55-59,60-64,65+$. Midpoints of each age group were used in estimating the structural time-series equation relating earning to age. Ministry of Labor data on earnings-which include contract wages and bonus wages --would slightly raise relative earnings for the middle-age groups (age $35-54$ ), but otherwise yields a very similar profile. 
For further analysis, the cross-sectional pattern between age and earnings that emerges from the data is taken as representative of the time-series pattern of an individual's wage earnings over the course of his or her lifetime. The profile essentially summarizes the nature and timing of the rise and fall in relative earnings that agents can expect as they become mature workers and then move (gradually) into retirement. For simplicity, it is assumed that this historically stable profile remains unchanged in the face of demographic changes. However, with healthier seniors living longer and pension benefits possibly declining, older workers may decide to postpone retirement. This would tend to flatten the age-earnings profile and, hence, mitigate the economic impact of population aging.

To calibrate an agent's life-cycle income profile, the following specification is estimated on the age-earnings data:

$$
r y(s, t)=a_{1} e^{-\alpha_{1}(t-s)}+a_{2} e^{-\alpha_{2}(t-s)}+\left(1-a_{1}-a_{2}\right) e^{-\alpha_{3}(t-s)}
$$

where $r y$ denotes relative labor income, $s$ and $t$ represent cohort and time indices, respectively, and their difference $t-s$ determines the age of a particular cohort. The restriction on the $a_{i}$ coefficients reflects the normalization that the youngest cohort (i.e., when $s=t$ ) has relative income equal to unity. The exponential form is chosen for analytical tractability of the model, and the specific choice of three exponent terms - allowing for three inflection or turning points - is chosen to provide a reasonable fit of the data. The fitted values of this equation are shown by the solid line in Figure 2. ${ }^{11}$

The estimated income-profile parameters from equation (1) enter the simulation in two distinct ways. On the supply side, the parameters directly affect the dynamics of aggregate labor supply-measured in efficiency units-since they reflect the relative productivity and labor supply of workers at different ages. ${ }^{12}$ On the demand side, since consumption is (partly) based on permanent income, these income-profile parameters also affect consumption-saving plans

${ }^{11}$ Non-linear least squares yield the following parameter estimates (corrected standard errors appear in parentheses):

$$
\begin{gathered}
\alpha_{I}=0.073^{* *}(0.001) ; \alpha_{2}=0.096^{* *}(0.002) ; \alpha_{3}=0.085^{* *}(0.001) \\
\bar{R}^{2}=0.92, D . W .=1.31, \text { S.E.E. }=0.18
\end{gathered}
$$

where $*(*)$ indicates significance at the $5(1)$ percent level. The $a_{i}$ coefficients were obtained through grid search $\left(a_{1}=a_{2}=200\right)$.

12 At issue is whether the empirical relation between age and relative earnings fully reflect differences in productivity and labor supply. The presence of seniority wages, for example, may be more a matter of prestige than productivity and may overstate the gains in productivity that accompany the rise in earnings of mature workers. On this score, however, it should be noted that the estimated earnings profile in Figure 2 tends to place the peak of relative earnings at an earlier age, when the productivity peak is more likely to occur. 
through their impact on human wealth--i.e., the present value of future labor income streams (see Faruqee (2001)).

\section{B. Pension System}

To complete the analytical framework, social security needs to be modeled. An advantage of the multi-cohort approach is that social security transfers can be straightforwardly included. In particular, a pension system can be introduced into the framework as follows. Consider the simple case of a lump-sum transfer scheme:

$$
\operatorname{tr}(s, t)= \begin{cases}-\alpha(t) ; & s>j \\ +\beta(t) ; & s \leq j\end{cases}
$$

where $\operatorname{tr}(s, t)$ represent the transfers paid or received by individuals, depending on their age relative to retirement age $j$. Younger generations pay into the system, while older agents or pensioners receive a benefit. For any transfer scheme, a full-financing condition can be written as follows:

$$
\int_{-\infty}^{t} \operatorname{tr}(s, t) N(s, t) d s=0,
$$

where $N(s, t)$ is the size of the cohort indexed by $s$. This general condition must hold for a transfer scheme to be deemed fully funded (i.e., no unfunded liabilities). In the case of lumpsum transfers, condition (3) requires that:

$$
\frac{\beta(t)}{\alpha(t)}=\frac{1-\phi(t)}{\phi(t)},
$$

where $\phi(t)$ and $1-\phi(t)$ are the shares of elderly dependents and working-age persons in the adult population. ${ }^{13}$ Full-financing requires, as shown by equation (4), the well-known condition that the benefit-to-contribution ratio must equal the support ratio, defined as the number of working-age persons relative to elderly dependents. ${ }^{14}$ Otherwise, there would exist a financing

${ }^{13}$ Specifically, the number of elderly is defined as follows: $\phi(t) N(t)=\int_{-\infty}^{\left({ }^{(t)}\right.} N(s, t) d s$, where $N(t)$ is the total population and $j(t)$ is an index denoting the new cohort of elderly dependents at a point in time. Using this definition, the age rule for transfers in equation (2), and the adding-up constraint in (3), one can obtain the full-financing condition shown in (4).

${ }^{14}$ The case of payroll tax financing is straightforwardly extended. In that case, individual contributions $\alpha(s, t)$ would be age-dependent, determined by social security taxes paid on individual labor income- $\tau y(s, t)$. In what follows, a social security transfer scheme along these lines is introduced into MULTIMOD, so that net taxes-i.e., taxes less transfers-replace the previous treatment of government revenues; social security benefits and contributions (as ratios 
gap that would need to be covered through other revenues or government borrowing. The amount of the financing gap is determined by:

$$
\operatorname{gap}(t)=\beta(t) \phi(t)-(1-\phi(t)) \alpha(t)
$$

A positive gap would indicate a shortfall of financing relative to benefits.

\section{Fiscal Accounts}

To provide a more detailed analysis of the fiscal accounts, the MULTIMOD framework is further combined with a more-disaggregated fiscal model. Policy assumptions affecting general government and social security finances are first fed into the small fiscal model which-under given macroeconomic assumptions- provides a long-term projection of fiscal accounts. ${ }^{15}$ The results of the fiscal model are then fed into MULTIMOD, which produces revised macroeconomic assumptions, and the process is repeated until a reasonable degree of convergence is achieved. However, "convergence" should not be understood in a mathematical sense, since MULTIMOD is already a rather complex framework and adding a fully specified fiscal sector would have made the simulation unwieldy. Therefore, some macro parameters in the fiscal model were simulated independently, although projections for key variables, such as growth and saving, were obtained directly from MULTIMOD.

\section{THE IMPACT OF AGING}

This section assesses the economic impact of demographic changes in Japan. Since MULTIMOD is designed to analyze the effects of macroeconomic shocks relative to a given baseline, the simulations have followed a two-step strategy. The first step involves the construction of a hypothetical reference scenario with a stationary population (see Annex 1). Realistic population projections are introduced in the second step, with MULTIMOD simulating the effects of the demographic "shock" relative to the reference scenario. In turn, the "shock" scenario will later serve as baseline for the policy simulations.

In order to isolate the impact of demographic changes on the economy, other exogenous factors-especially the fiscal deficit path - are identical in the reference and shock scenarios. It is assumed that the government embarks on slow consolidation and only gradual fiscal reform, building on the government's plans (e.g., for pension reform) as far as they are currently discernible. The social security surplus-to-GDP ratio is also held common across both scenarios, leaving tax rates and other fiscal variables to adjust to maintain the assumed deficit path. Different fiscal policy choices are discussed in the next chapter.

to GDP) are taken as exogenous policy parameters. In terms of behavior, these benefit and contribution rates mainly affect private behavior through their implications for permanent income.

${ }^{15}$ The fiscal model improves upon an earlier long-term simulation by Fund staff (e.g., Meredith 1995) by using a more disaggregated model for the social security finances (Mühleisen, 2000b). 


\section{A. Growth and Saving}

The results of the MULTIMOD simulations are summarized in Table 3. With a declining and aging population, the level of real GDP is projected to fall by about 20 percent cumulatively (relative to the reference scenario) in the long run:

- Initially, output and investment rise owing to the fact that effective labor supply is growing at the outset relative to the stationary population assumed in the reference scenario.

Significant aging also does not occur till after 2015. An increase in effective labor supplysomewhat akin to a positive shock to labor productivity - tends to reduce the interest rate and boost saving and investment.

- Eventually, the decline in effective labor with population aging and contraction (similar to a negative productivity shock) leads to a rise in interest rates as saving and investment levels decline with output. Therefore, the decline in GDP largely occurs between 2025 and 2075 , when the demographic changes are most pronounced. In growth terms, annual GDP growth on average is lower by about 0.5 percentage points per year, before the economy settles to a longer-run equilibrium with a permanently higher elderly dependency ratio.

Table 3. Simulated Effects of Population Aging in Japan

(Percent deviation from scenario with stable demographics; unless noted otherwise)

\begin{tabular}{lrrrrrrrr}
\hline \multicolumn{1}{c}{ Variable } & 2001 & 2005 & 2010 & 2015 & 2025 & 2050 & 2075 & 2100 \\
\hline Real GDP $^{\text {Interest Rates }}{ }^{1}$ & -0.7 & 1.4 & 1.6 & 1.7 & -0.9 & -11.2 & -17.4 & -18.4 \\
Contribution to GDP: $_{\text {Consumption }^{2}}$ & -0.2 & -0.2 & -0.3 & -0.5 & -0.4 & -0.2 & 0.0 & 0.0 \\
Investment $^{2}$ & & & & & & & & \\
Net Exports $^{2}$ & -1.0 & 0.3 & 0.8 & 0.9 & -0.9 & -8.8 & -13.9 & -14.7 \\
CPI Inflation $^{1}$ & 0.0 & 0.4 & 0.3 & 0.4 & 0.1 & -1.4 & -2.4 & -2.6 \\
GPD per adult $_{\text {Real Exchange Rate }}$ & 0.3 & 0.7 & 0.5 & 0.4 & 0.0 & -1.0 & -1.1 & -1.1 \\
C/A Balance $^{1}$ & 0.2 & -0.1 & -0.0 & -0.1 & -0.1 & -0.0 & 0.0 & 0.0 \\
Private Saving Rate $^{1}$ & -1.0 & 0.0 & 0.0 & 0.2 & 0.0 & -1.4 & -1.2 & -1.5 \\
Dependency Ratio $^{1}$ & -2.4 & -2.6 & -2.0 & -1.6 & 0.8 & 7.7 & 10.5 & 11.2 \\
Population Growth $^{1}$ & 0.2 & 0.4 & 0.4 & 0.5 & 0.5 & 0.3 & 0.2 & 0.4 \\
\hline & 0.5 & 0.6 & 0.5 & 0.6 & 0.6 & 0.5 & 0.4 & 0.5 \\
\hline
\end{tabular}

${ }^{\mathrm{I}}$ Percentage point deviation from baseline; interest rates are long-term nominal rates.

${ }^{2}$ Deviation from baseline value in percent of baseline GDP.

Note: The table shows the impact of the shock on the Japan block of the model in isolation-i.e., treating world variables as exogenous and without further feedback. Adding demographic dynamics simultaneously for the other industrial countries would change some of the implications of the model, particularly for external variables, but the differences are small. 
In per capita terms, GDP per adult declines slightly in the long run (relative to the reference scenario) for the following reason. The percent decline in output is in line with the contraction of labor, measured in efficiency units. However, the percent decline in effective labor is larger than the fall in the number of workers, given the aging of the workforce and the differences in labor productivity and supply across age groups implicit in the age-earnings profile. Extending the simulation further out (i.e., closer to steady state) would show the decline in per capita GDP to be about 5 percent relative to the reference scenario, as the output-labor ratio returns to its baseline level. ${ }^{16}$

Investment and saving levels (relative to the reference scenario) also decline in the long run with GDP. The fall in investment reflects the desire to shed capital in the face of declining labor and output in the economy; the rate of investment (as a share of GDP) though is more or less unchanged. Saving rates, however, increase slightly as the population ages. Despite a higher proportion of elderly who tend to save less, the decline in the inflow of young agents (who tend to have high consumption propensities) and the increase in longevity act to raise saving rates. ${ }^{17}$ Consequently, the current account surplus increases, mainly reflecting the rise in private saving. Correspondingly, the real exchange rate would depreciate initially before appreciating in the long run with the accumulation of net foreign assets.

\section{B. Fiscal Impact}

The 2000 pension reform has reduced the government's unfunded pension liabilities to some 60-70 percent of GDP but, this still implies that large contribution rate increases are necessary to prevent pension assets from being depleted. On the basis of the current benefit and transfer structure, the baseline simulation shows that contribution rates to the main employee pension system would need to rise from $17 \frac{1}{2}$ percent to close to 30 percent over the next 50 years (as opposed to $251 / 2$ percent currently projected by the government). Medical contribution rates would have to go up by a similar proportion, mainly as a result of the steep rise in old-age medical costs. Despite these increases, financial balance in the social security system would depend on a doubling of government transfers to more than 5 percent of GDP a year, which shows that the fiscal situation will become considerably more complicated as the demographic transition sets in. ${ }^{18}$

Accordingly, once the economy has recovered, the government is assumed to conduct fiscal consolidation before population aging intensifies after 2010 . However, even if the government

${ }^{16}$ With the initial decline in interest rates, the economy experiences some capital deepening (i.e., rise in the capital-labor ratio), and thus, a rise in GDP per effective unit of labor. But because productivity is exogenous and the interest rate is fixed (equal to the world rate) in the long run, the capital-labor ratio is predetermined in the long-run by the production function.

${ }^{17}$ An increase in longevity-i.e., a decline in the mortality rates in the model-increases agents' planning horizons and lowers their effective discount rate, which raises saving rates.

${ }^{18}$ For a full description of the fiscal simulation results, see Mühleisen (2000b). 
would manage to reduce its fiscal deficit to about 3 percent of GDP within a decade, net debt would only stabilize around 120 percent of GDP - a level that would leave public finances vulnerable to interest rate shocks and policy slippage. The need to cover contingent liabilities, e.g., those related to government guarantees or the Fiscal Investment and Loan Program, could further increase public debt levels.

Reducing public debt over the long run would require significant additional measures. Following the initial consolidation round, the room for further expenditure cuts appears limited as welfare obligations are likely to remain high, and payroll taxes will already be driven up by rising social security contributions). As a result, the consumption tax rate is projected to rise from the current 5 percent to about 25 percent over 50 years, which would be high but still comparable to today's VAT levels in some industrial countries. ${ }^{19}$

It is clear that the policies assumed in this simulation-slow debt consolidation and gradual social security reform-would be a long-term drag on living standards as high social security contribution rates and indirect taxes would create economic disincentives. What could be gained by pursuing different policies and at what cost? To respond to these questions, the next section presents alternative policy paths - both for restoring the long-term viability of the social security system and for stabilizing government debt-and analyzes their impact on growth and welfare relative to this policy baseline.

\section{Policy ANalysis}

\section{A. How to Address the Aging Problem?}

The debate over social security reform in Japan has focused mainly on two questions. First, to what extent should future benefits be cut, and second, how to finance the rise in social security expenditure? These questions are related as it is generally agreed that significantly higher payroll taxes (as in the baseline scenario) would have undesirable effects on work incentives and labor costs, which implies either a reduction in future benefit levels or an increase in government transfers:

- Benefit cuts. There have been various suggestions of how to cut net pension benefits, including through reductions in the gross replacement ratio, higher taxation of pension incomes, an increase in the retirement age, or a shift to privately-financed pension schemes. Potentially large savings could be achieved by shifting all remaining pension components from wage to price indexation (including National Pension benefits and entry levels of earnings-related pensions; Yashiro et al. 1997). An increase in the retirement age would also contribute to overall labor supply and output, but this effect is likely to be small as the participation rate of elderly Japanese in the labor force is already quite high.

${ }^{19}$ As with every long-term simulation, the results are highly dependent on the underlying assumptions. See Annex 2 for a sensitivity analysis. 
- Higher government transfers. Maintaining high benefits at lower contribution rates would require an increase in government transfers to the social security system. These would have to be financed through indirect taxes to avoid the disadvantages associated with higher payroll taxes and to spread the burden of financing social security benefits over the general population (including pensioners themselves).

This debate is reflected in the following two simulations:

- First, one scenario assumes a reduction of social security benefits by 2 percent of GDP over a period of 20 years relative to the baseline scenario, which would allow a commensurate decline in social security contributions.

- The second scenario keeps social security benefits unchanged relative to the baseline, but assumes that consumption taxes would be raised to finance a reduction in social security contributions identical to that in the first scenario. In this way, the scenarios analyze the trade-off between the level of social security benefits and consumption tax increases that appears to be at the heart of the pension debate in Japan.

The results suggest that benefit reductions, coupled with a decline in social security contributions, would clearly offer the most beneficial reform alternative with regard to growth and economic welfare measures (proxied by private consumption and wealth; Figure 3$){ }^{20}$ The chart shows that both simulated reforms would result in higher long-term growth relative to the baseline, but the effects would be larger in the case of benefit reductions, where private saving increases. ${ }^{21}$ While benefit cuts would imply a short-term output decline (owing to a drop in consumption), the positive long-term effects on output would be substantially larger, owing to a fall in interest rates that would provide a boost to

\footnotetext{
${ }^{20}$ The two scenarios incorporate female labor supply reactions. On the basis of time-series regressions, female labor supply elasticity with respect to disposable income was estimated at 0.1 . For illustration, the charts also show simulation results for an elasticity twice that size.

${ }^{21}$ The endogenous increase in saving rates with a balanced reduction in contributions and benefits can be understood as follows. The reform redistributes disposable income from pensioners who receive less transfer income to workers who face lower payroll taxes. This latter group generally have higher marginal saving propensities. In addition to this distributional aspect, saving across all age groups would generally rise as individuals, faced with less generous pension benefits now or in the future, need to save more for their own retirement and future consumption. Quantitatively, simulations suggest that private saving increases by nearly half the amount of the reduction in benefits. These saving effects are close to those implied by cross-country estimates reported in Feldstein (1980).
} 
Figure 3. Japan: Macroeconomic Effects of Social Security Reform

(Difference to baseline scenario, in percent)
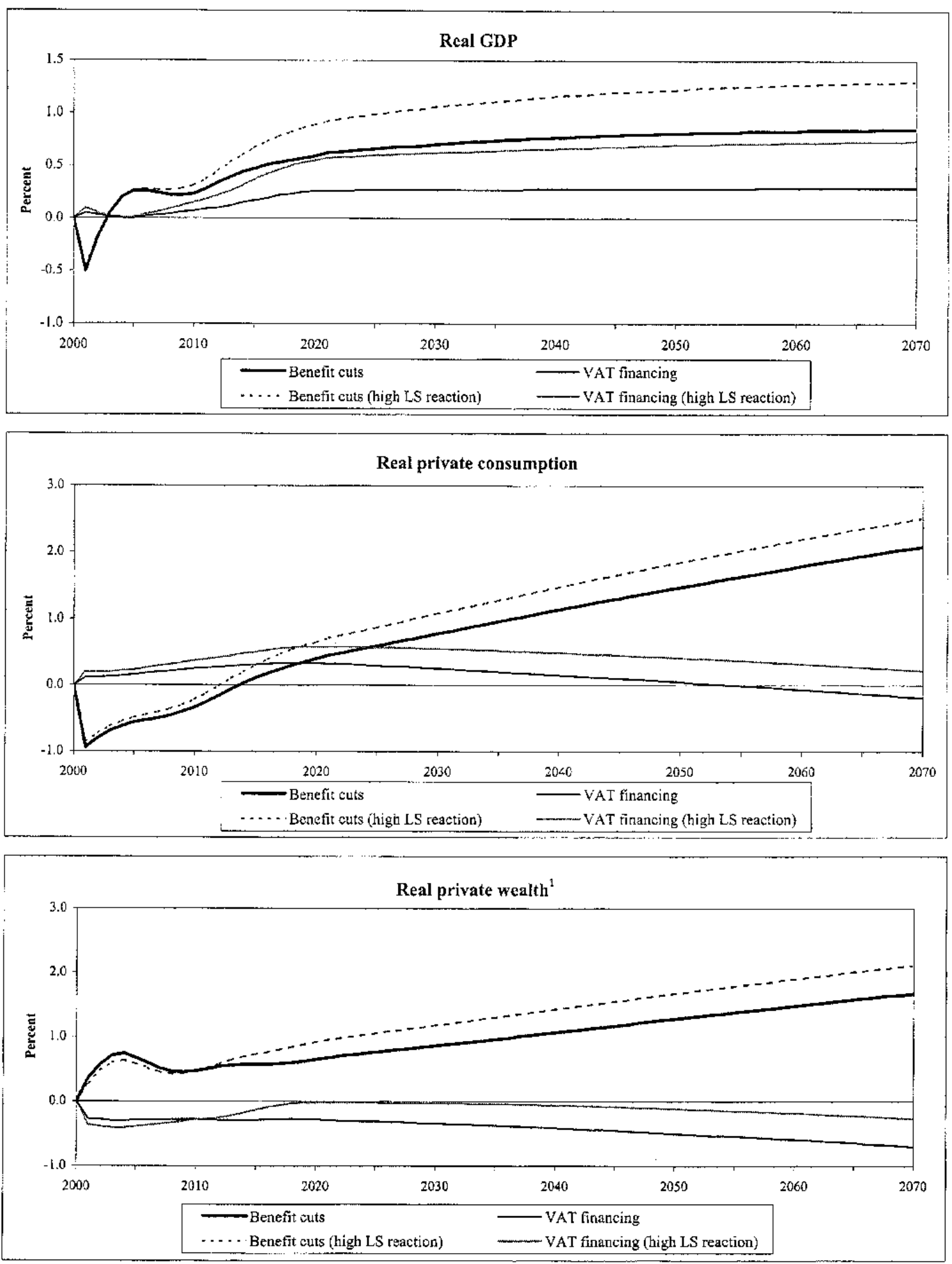

Source: Staff calculations.

Real firancial assets phus discounted real income over the projection period. 
investment. ${ }^{22}$ In the case of the consumption tax increase, private saving would decline relative to baseline, since the pension financing would be partly shifted from workers to pensioners who generally have a lower marginal propensity to save. Higher growth over the long term would thus mainly be an effect of increased labor supply as a consequence of lower payroll taxes.

In contrast to benefit cuts, a reduction in social security contributions financed by a consumption tax increase would have mixed effects on private consumption and wealth. The initial decline in saving implies that interest rates rise and that there is less of a buildup in capital stock compared to the baseline (which translates into a valuation loss of financial assets and thus lower wealth). Moreover, the increase in interest rates leads elderly consumers-who are less liquidity constrained-to increase consumption, thus further reducing aggregate saving. ${ }^{23}$ The resulting decline in the current account surplus also depresses financial wealth through a drawdown of foreign assets. Eventually, the fall in wealth would imply that consumption would drop relative to baseline, although this would only occur towards the end of the projection period.

Although the results may depend to some extent on the particular specification of the model, the main policy conclusion is that a reduction of social security benefits would generate lasting output and welfare gains, although at the risk of some small short-term output losses that would need to be minimized through careful phasing. As frequently pointed out in the literature, benefit cuts would also be the most equitable way of distributing the pension burden across generations. By contrast, financing social security through an increase in the consumption tax would also result in output gains relative to payroll tax financing, but welfare effects would not be permanently positive.

\section{B. Speed and Composition of Fiscal Consolidation}

In view of Japan's long-term fiscal imbalance, any move to address the fiscal deficit will not only have a direct impact on aggregate demand, but will also effect on individuals' current and future savings behavior. The choice of policies for stabilizing the fiscal situation is therefore important, especially if the government decides to pursue a somewhat faster pace of consolidation to reduce its exposure to fiscal risks. The potential benefits of such a policy include positive debt dynamics, higher public saving, and less need for precautionary saving on the part of individuals. However, as the 1997 experience has shown, there could be a drawback

\footnotetext{
${ }^{22}$ As a result of rational expectations and full information, long-term policy changes are immediately reflected in agents' decisions, leaving intertemporal patterns front-loaded and exaggerated. For example, a substantial pension reform could have beneficial output effects in the short run, owing to improvements in confidence as the social security system would be more plausibly funded. However, such effects are not captured in MULTIMOD.

${ }^{23}$ MULTIMOD is set up in a way that the income effect of higher interest rates on saving significantly exceeds the substitution effect. This is consistent with the large reliance of elderly Japanese households on accumulated assets for retirement income.
} 
if strong fiscal adjustment measures would stall the recovery, making eventual fiscal consolidation all the more difficult to sustain.

To illustrate the macroeconomic trade-offs, the simulation framework has been used to compare the effects of policies that are assumed to stabilize general government debt over a period of five years compared to 10 years in the baseline. This is assumed to be achieved in turn through one of the following policy measures: (i) cuts in public investment; (ii) an increase in the consumption tax rate; and (iii) direct tax base broadening. ${ }^{24}$ Faster consolidation would stabilize debt at a lower level than in the baseline, and it is assumed that this positive debt differential is maintained through the end of the forecasting period. All other assumptions (regarding social security parameters, etc.) remain unchanged from the baseline scenario.

As expected, faster consolidation would result in sustained gains to economic output over the medium-term, although at the cost of short-term losses (Figure 4). Real output would decline relative to the baseline scenario for the first 3-4 years of the adjustment process, but rise above baseline output for the rest of the forecasting period. The largest long-term gains would be achieved in the case of public investment cuts, but these would also entail the largest short-term output losses, with real GDP being $1 \frac{1}{4}$ percentage points below baseline output in the first year of the adjustment process. ${ }^{25}$ The cases of tax base broadening and consumption tax increases would imply a much smaller initial output loss, but long-term gains would also be smaller, owing to the distortionary effects of higher taxes.

Long-term gains in private consumption and private wealth also highlight the beneficial role of public investment cuts. In the first scenario, both welfare measures improve strongly relative to the baseline scenario, whereas the other two strategies result in lower consumption for most of the time, and yield significantly smaller wealth gains. ${ }^{26}$ The reason is that tax increases either directly reduce disposable labor income (in the case of direct taxes), or decrease future real incomes through an increase in consumer prices (in the case of consumption taxes).

Three main policy conclusions can be drawn from these findings:

\footnotetext{
${ }^{24}$ The case of higher direct tax rates was also considered, but produced an inferior outcome compared to both consumption tax increases and base broadening measures.

${ }^{25}$ In MULTIMOD, the public capital stock is not part of the production function, i.e., public investment does not raise economic output over the long term. Economic gains of lower public investment could be somewhat overstated as a result.

${ }^{26}$ Gains in private wealth are positive even in the case of tax increases, because they include discounted future earnings which increase if GDP is higher relative to the baseline.
} 
Figure 4. Japan: Macroeconomic Effects of Fiscal Consolidation Strategies (Difference to baseline scenario, in percent)
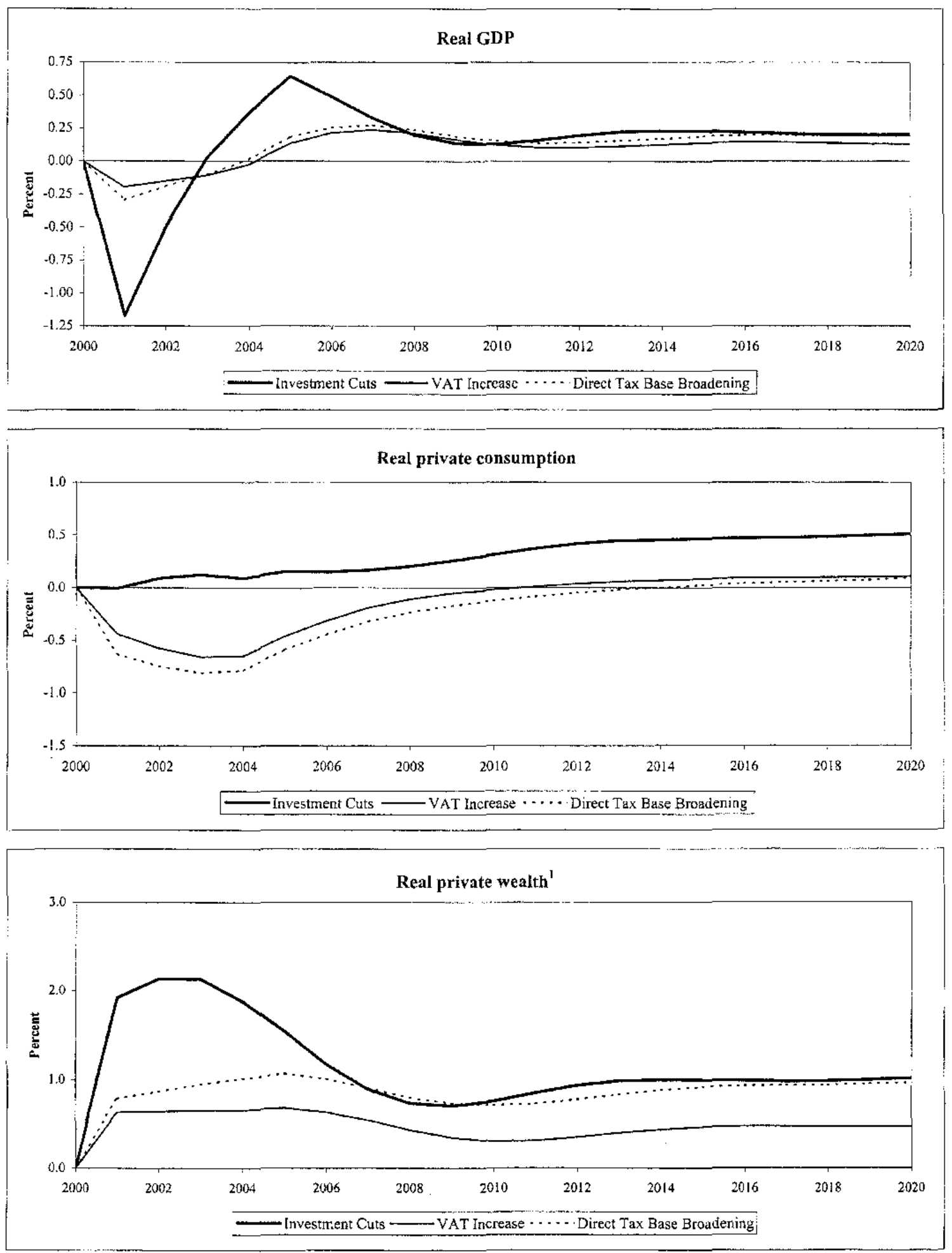

Source: Staff calculations.

'Real financial assets plus discounted real income over the projection period. 
- A shortening of the fiscal adjustment horizon implies short-term output costs-suggesting that sharp tightening measures should be held back until private demand has reached sustainable levels.

- The risk to short-term output growth is largest in the case of investment cuts, despite the fact that these also generate the strongest long-term welfare gains. From an economic perspective, tax increases would provide a less risky instrument to achieve fiscal consolidation in the initial phase of an upswing. Investment cuts should be phased in more gradually, depending on the progress of the recovery. ${ }^{27}$

- In terms of taxation measures, the simulations indicate that a consumption tax increase would have somewhat less beneficial effects than a broadening of the direct tax base. This highlights the fact that the VAT - although generally considered to be close to an optimal tax - does carry distortionary effects as it introduces a wedge between producer and consumer prices. The model suggests that efficiency losses from base broadening (which could result from lower tax exemptions) are smaller, although only by a small margin.

\section{Conclusions}

Demographic changes will be a defining feature in Japan for the foreseeable future. A sustained decline in fertility rates underlies a rapid aging and decline of Japan's population that can be expected to continue well into the new century. This dramatic demographic shift will have profound social and economic implications, but the transition appears manageable if appropriate policy measures are taken in time:

- As the workforce contracts, output growth will slow: absent any significant acceleration in total factor productivity, annual growth rates would be lower by about one-half percent over the next half century. In per capita terms, GDP per person could also decline (relative to the case of no demographic changes) since the rising share of the elderly suggests an even larger decline in effective labor supply than implied by the shrinking numbers of the workforce. However, long-term growth prospects would be boosted if structural reforms and advances in technology led to a sustainable increase in total factor productivity.

- Contrary to what is usually assumed in the literature, saving rates and the current account ratio need not decline significantly with an aging population. Though a higher share of older persons in the population would tend to reduce saving rates, other aspects of demographic changes in Japan, such as fewer young adults (and young dependents) and increased longevity, could counterbalance the negative effects of population aging on saving rates.

\footnotetext{
${ }^{27}$ This is consistent with the view that public works have de facto substituted for fiscal stabilizers in the recent past, and should thus only be reduced gradually in an economic upswing (Mühleisen 2000a).
} 
- High public debt and adverse population dynamics increasingly constrain the government's room for maneuver, suggesting that strong policy adjustments will eventually be required to put public finances back on a sustainable footing. Reforms currently being implemented in the pension and health systems are a step in the right direction, but further measures will be needed. In this context, the importance of growth-enhancing structural change can not be overemphasized. As the example of the U.S. in the 1990s has shown, public debt dynamics can improve substantially once the economy grows at a sustainably fast pace.

Model simulations also suggest that ambitious debt stabilization, particularly through cuts in public expenditure, and sharp reductions in social security benefits could result in substantial short-term output costs, posing a risk to the recovery. This is particularly true in the case of public investment cuts, where the multipliers are generally believed to be larger. Therefore, as long as private demand remains fragile, fiscal adjustment policies would have to be implemented cautiously.

However, in view of the serious aging problem, once the recovery is on a sound footing, Japan will need to implement a long-term fiscal strategy to make public finances sustainable. This paper suggests that public investment cuts, base broadening measures for income taxes, some increase in the consumption tax, and reductions in social security benefits, are likely to be the key building blocks of the longer-term solution. 


\section{DEMOGRAPHIC IMPACT AND COUNTERFACTUAL SCENARIOS}

To calibrate the magnitude of demographic changes and their effects, one can construct for comparison purposes counterfactual scenarios wherein certain demographic variables remain unchanged. Using this reference scenario as an artificial baseline, one could then simulate the economic impact of Japan's demographic projections, as determined by the behavioral features of the model and given unchanged policies. ${ }^{28}$ These simulation results are helpful in projecting--in model-consistent fashion-the future paths of key macroeconomic variables (e.g., interest and growth rates) under population aging when considering issues such as pension reforms.

The counterfactual exercise is described here in the appendix and is done in two different ways. In the first simulation, a stationary population is used as the reference scenario to help identify the effects of both population contraction and aging; in the second simulation, the effects of population aging alone are isolated. Japan's demographic dynamics contain components of both phenomena.

\section{Population Contraction and Aging}

To examine the effects of a declining and aging population and work force implied by Japan's demographic projections, a counterfactual scenario is constructed where the birth and death rates are chosen so that the rise in the dependency ratio is curtailed somewhat and the population does not contract. Specifically, in the initial steady state, it is assumed the population is stationary with the birth rate $(b)$ constant at its 2000 level; the death rate $(p)$ is also set equal to this value (i.e., $b-p=n=0$ ).

Figure 5 shows the evolution for the Japan's birth rate and population growth rate under the counterfactual baseline scenario as well as under the alternative scenario of population aging. Figure 6 shows the evolution of

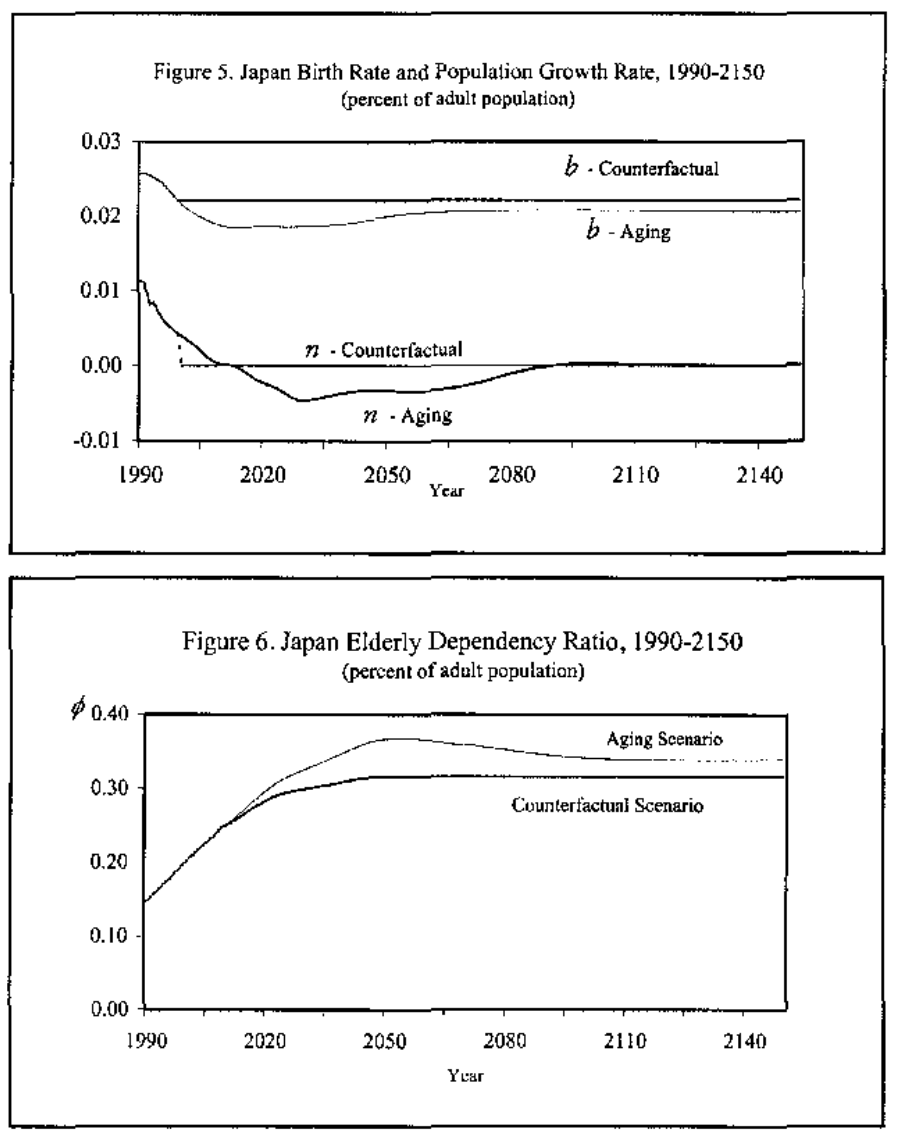

${ }^{28}$ The basic simulations are conducted in a model without pensions to isolate the economic effects of population aging alone. A pension transfer scheme is later introduced when examining policy shocks. 
the elderly dependency ratio $\phi$ under both scenarios. Note that since the fertility rate has already declined (as part of history), some aging will also occur under the baseline scenario since the full effects on the dependency rate come only with a lag--i.e., the present dependency ratio is still below its long-run level even if the population is stationary from this point forward.

Comparing the two scenarios, one sees that the demographic shock underlying the aging scenario involves a continued decline in the birth rate. Population growth is initially positive and higher under the aging scenario before declining and turning negative below the zero growth rate maintained throughout the baseline scenario. This suggests that the mortality rate is also lower initially (i.e., greater longevity) under the population aging scenario than in the case of a stationary population. The fact that population growth eventually goes to zero in the aging scenario at a lower long-run birth rate further requires that the long-run death rate also remain lower than in the baseline.

\section{Population Aging}

To better isolate the impact of a changing age distribution, a second counterfactual or baseline scenario can be constructed where the population growth rate is identical to the aging scenario, but where the rise in the dependency ratio is muted. This is done by assuming a higher birth rate in the second reference scenario than in the aging case; correspondingly, the death rate is sufficiently raised so that the same population growth rate obtains. The paths for the $b$ and $n$ in these two scenarios are shown in Figures 7 and 8.

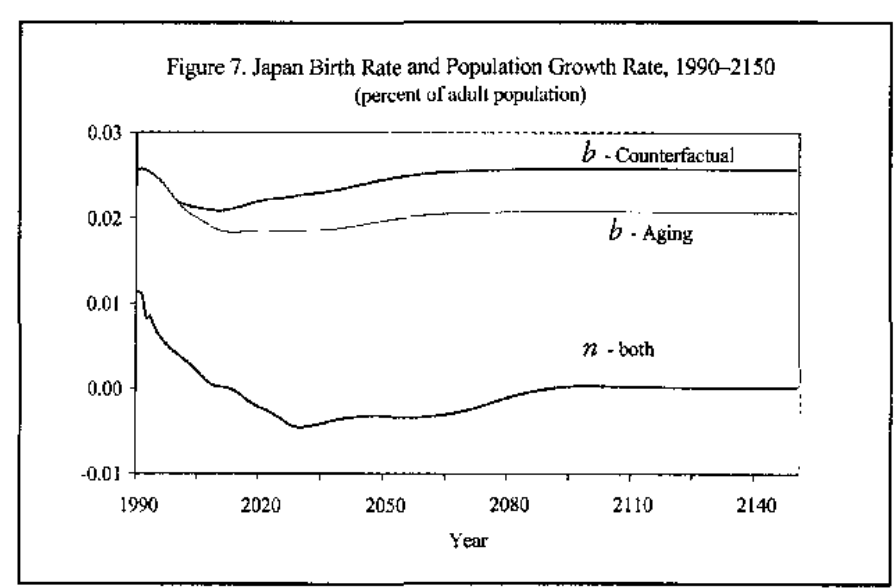

Comparing these figures to those associated with the previous counterfactual scenario, one sees that the aggregative implications of a decline in the birth rate are removed in the second experiment, but the distributional implications are accentuated. In other words, the rise in the dependency ratio in the aging scenario is relatively much larger against the second counterfactual scenario than the first (Figure 8 vs. Figure 6), but the growth differences are completely negated (Figure 7).

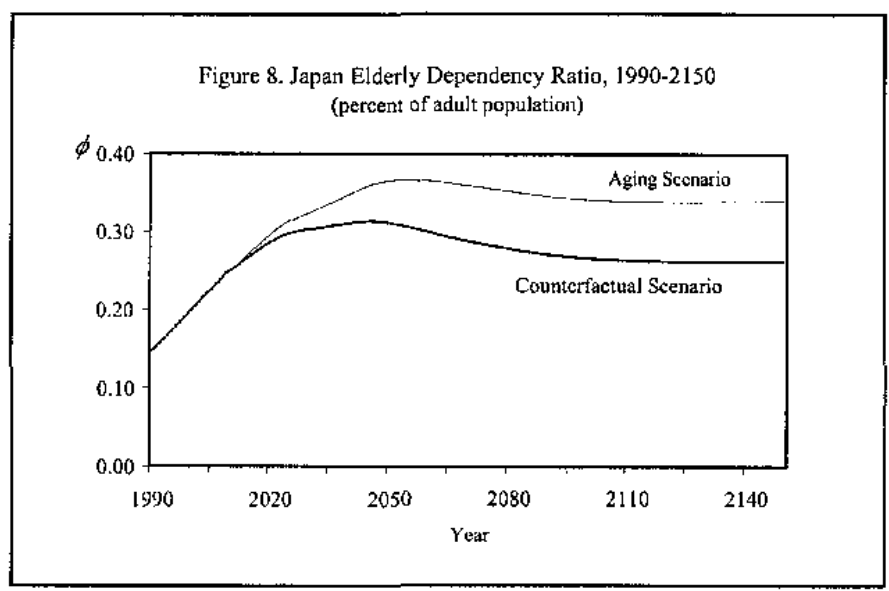


The comparative effects of both counterfactual scenarios versus the aging scenario is summarized below in Table 4. The top half of the table shows the effects attributable to both population aging and decline relative to baseline; the bottom half of the table shows the effects due solely to aging. The results indicate that almost half of the long-run fall in GDP is due to an aging workforce and not just a shrinking workforce.

In terms of saving behavior, because mortality falls (i.e., longevity rises) to a greater extent (see Figure 7) in the second simulation-i.e., the second reference scenario versus the aging scenario-private saving will rise more in this case. As the death rate $p$ falls, the planning horizon lengthens and the effective discount rate declines. Longer horizons and more patience on the part of agents tend to raise their saving propensities. In the simulations, this can be seen by the larger initial fall in consumption and improvement in net exports in the bottom half of the table. In the long-run, though, consumption falls by less because national income (and output) are higher as net foreign assets are accumulated.

\begin{tabular}{|c|c|c|c|c|c|c|c|}
\hline \multicolumn{8}{|c|}{$\begin{array}{l}\text { Table 4. Comparative Effects of Demographic Changes in Japan } \\
\text { (percentage point deviation from baseline; unless noted otherwise) }\end{array}$} \\
\hline Variable & 2005 & 2010 & 2015 & 2025 & 2050 & 2075 & 2100 \\
\hline & \multicolumn{7}{|c|}{ Population Aging and Contraction } \\
\hline Real GDP & 1.4 & 1.6 & 1.7 & -0.9 & -11.2 & -17.4 & -18.4 \\
\hline Contribution to GDP: & & & & & & & \\
\hline Consumption $^{2}$ & 0.3 & 0.8 & 0.9 & -0.9 & -8.8 & -13.9 & -14.7 \\
\hline Investment ${ }^{2}$ & 0.4 & 0.3 & 0.4 & 0.1 & -1.4 & -2.4 & -2.6 \\
\hline Net Exports ${ }^{2}$ & 0.7 & 0.5 & 0.4 & 0.0 & -1.0 & -1.1 & -1.1 \\
\hline Dependency Ratio $^{1}$ & 0.0 & 0.1 & 0.7 & 2.0 & 5.1 & 4.0 & 2.5 \\
\hline \multirow[t]{2}{*}{ Population Growth ${ }^{1}$} & 0.2 & 0.0 & -0.1 & -0.4 & -0.3 & -0.2 & 0.0 \\
\hline & \multicolumn{7}{|c|}{ Population Aging } \\
\hline Real GDP & 2.7 & 1.4 & 1.5 & -0.6 & -6.0 & -7.9 & -8.1 \\
\hline \multicolumn{8}{|l|}{ Contribution to GDP: } \\
\hline Consumption $^{2}$ & -4.2 & -4.2 & -3.7 & -3.7 & -4.2 & -3.3 & -2.0 \\
\hline Investment $^{2}$ & 1.2 & 0.6 & 0.8 & 0.5 & -0.3 & -0.6 & -0.6 \\
\hline Net Exports ${ }^{2}$ & 5.6 & 5.0 & 4.4 & 2.6 & -1.6 & -4.0 & -5.5 \\
\hline Dependency Ratio ${ }^{1}$ & 0.0 & 0.1 & 0.5 & 1.5 & 5.6 & 7.3 & 7.6 \\
\hline Population Growth ${ }^{1}$ & 0.0 & 0.0 & 0.0 & 0.0 & 0.0 & 0.0 & 0.0 \\
\hline
\end{tabular}




\section{SENSITIVITY ANALYSIS}

Long-term simulations yield indicative results at best, given their sensitivity to underlying assumptions. The focus should thus be on broad macroeconomic trends rather than on any single forecast. To illustrate this point, two critical assumptions have been modified in the baseline simulation:

- Weaker demographics. The population projection used in the baseline scenario projects a recovery in the fertility rate over the next 25 years. However, there is little evidence so far to suggest that a reversal in this trend is about to occur (Yashiro et al. 1997). By comparison, it is assumed that the fertility rate stabilizes at 1.3 percent, which would result in an increase in the age dependency ratio to 80 percent by 2050 (20 percentage points higher than in the baseline model).

- Technology change. A second scenario assumes TFP growth at 1 percent, or 20 basis points higher than the historic average used in the baseline scenario. As the Japanese economy is likely to become more capital intensive, particularly through investment in new technologies, and with a gradually advancing structural reform process, it would not be unrealistic to expect TFP growth to accelerate in the future.

Table 5 highlights changes in some relevant fiscal parameters through the first half of the century (under the assumption that the path for the social security and general government balance remains roughly unchanged). The wide range of possible outcomes underscores the need to discuss policy choices in terms of relative rather than absolute variables.

\begin{tabular}{|lccc|}
\hline \multicolumn{4}{|c|}{ Table 5. Sensitivity Analysis: Social Security Indicators, 2050 } \\
(In percent) & Baseline & $\begin{array}{c}\text { Weaker } \\
\text { Demographics }\end{array}$ & $\begin{array}{c}\text { Higher } \\
\text { TFP Growth }\end{array}$ \\
\hline & & & \\
\hline Real benefit levels per beneficiary $(2000=100)$ & 126.3 & 108.6 & 130.1 \\
$\quad$ Pension (average) & 178.3 & 162.1 & 180.1 \\
$\quad$ General health insurance & 196.6 & 168.4 & 196.4 \\
$\quad$ Old-age medical care & & & \\
Contribution rates & 28.5 & 35.0 & 28.2 \\
$\quad$ Pensions (EPI) & 13.0 & 15.1 & 12.3 \\
$\quad$ Health (average) & & & 6.4 \\
Government transfers to social & 7.6 & 8.4 & 17.8 \\
$\quad$ security (percent of GDP) & 24.6 & 29.4 & 1.1 \\
Consumption tax rate & & & \\
Memorandum item: & 0.9 & 0.8 & \\
Average per-capita growth rate, 2000-50 & & & \\
\hline Source: Staff caiculations. & & & \\
\hline
\end{tabular}




\section{References}

Aaron, H.J., B.B. Bosworth and G. Burtless, Can America Afford to Grow Old? Paying for Social Security, The Brookings Institution, Washington, D.C., 1989.

Abel, A.B., "Precautionary Saving and Accidental Bequests", American Economic Review, 75, 777-91, 1985.

Attanasio, O., J. Banks, C. Meghir, and G. Weber, Humps and Bumps in Lifetime Consumption, NBER Working Paper 5350, 1995.

Blanchard, O., "Debt, Deficits and Finite Horizons", Journal of Political Economy, 93, 223-47, 1985.

Browning, M., and A. Lusardi, "Household Saving: Micro Theories and Micro Facts", Journal of Economic Literature, XXXIV:4, 1797-1855, 1996.

Chand, S.K., and A. Jaeger, Aging Populations and Public Pension Schemes, IMF Occasional Paper 147, Washington, D.C., 1996.

Cutler, D.M., J.M. Poterba, L.M. Sheiner, and L.H. Summers, "An Aging Society: Opportunity or Challenge?", Brookings Papers on Economic Activity, 1-73, 1990.

Davies, J., "Uncertain Lifetimes, Consumption and Dissaving in Retirement", Journal of Political Economy, 89, 561-78, 1981.

Diamond, P. A., "National Debt in a Neoclassical Growth Model", American Economic Review, $55,1126-50,1965$.

Faruqee, H., "Population Aging and Its Macroeconomic Implications: The Case of Japan", in: Japan-Selected Issues, IMF Staff Country Report 00/144, 2000.

Faruqee, H., "Population Aging and Its Macroeconomic Implications: A Framework for Analysis," IMF, mimeo, 2001.

Faruqee, H., D. Laxton, and S. Symansky, "Government Debt, Life-Cycle Income and Liquidity Constraints: Beyond Approximate Ricardian Equivalence”, IMF Staff Papers, 44:3, 374-82, 1997.

Faruqee, H., and D. Laxton, "Life-Cycles, Dynasties, Saving: Implications for Closed and Small Open Economies”, IMF Working Paper 00/126, 2000.

Feldstein, M.S., "International Differences in Social Security and Saving", Journal of Public Economics, 14, 225-44, 1980.

Hayashi, F., "Why Are Japan's Saving Rates So Apparently High", in S. Fischer, ed., NBER Macroeconomics Annual, Cambridge, MA: MIT Press, 1986.

Jappelli, T., "Who is Credit Constrained in the U.S. Economy?", Quarterly Journal of Economics, 105, 219-34, 1990.

Kohl, R., and P. O'Brien, The Macroeconomics of Ageing, Pensions and Savings: A Survey, OECD Ageing Working Papers AWP 1.1, 1998. 
Laxton, D., and others, MULTIMOD Mark III: The Core Dynamic and Steady-State Models, IMF Occasional Paper 164, 1998.

Leibfritz, W., Ageing Populations, Pension Systems and Government Budgets: How Do They Affect Saving?, OECD Economics Department Working Papers 156, 1995.

Masson, P.R., and R.W. Tryon, "Macroeconomic Effects of Projected Population Aging in Industrial Countries", IMF Staff Papers, 37:3, 453-85, 1990.

Meredith, G., "Alternative Long-Run Scenarios", in: U. Baumgartner and G. Meredith (eds.), Saving Behavior and the Asset Price "Bubble" in Japan: Analytical Studies, IMF Occasional Paper 124, 1995.

Mühleisen, M., "Too Much of a Good Thing? The Effectiveness of Fiscal Stimulus", in: T. Bayoumi and C. Collyns (eds.), Post-Bubble Blues: How Japan Responded to Asset Price Collapse, International Monetary Fund, Washington, D.C., 2000a.

Mühleisen, M. "Sustainable Fiscal Policies for an Aging Population", in: Japan-Selected Issues, IMF Staff Country Report 00/144, $2000 \mathrm{~b}$.

OECD, Maintaining Prosperity in an Ageing Society, Paris, 1998.

Roseveare, D., and others, Ageing Populations, Pension Systems and Government Budgets: Simulations for 20 OECD Countries, OECD Economics Department Working Papers $168,1996$.

Takayama, N., The Morning After in Japan: Its Declining Population, Too Generous Pensions and a Weakened Economy, Maruzen, Tokyo, 1998.

Yashiro, N., and A.S. Oishi, "Population Aging and the Savings-Investment Balance in Japan", in: M.D. Hurd and N. Yashiro (eds.), The Economic Effects of Aging in the United States and Japan, University of Chicago Press, Chicago and London, 1997.

Yashiro, N., T. Oshio, and M. Matsuya, Macroeconomic and Fiscal Impacts of Japan's Aging Population with a Specific Reference to Pension Reforms, Discussion Paper No. 78, Economic Research Institute, Economic Planning Agency, Tokyo, 1997. 